\title{
Widespread loss of the silencing epigenetic mark H3K9me3 in astrocytes and neurons along with hippocampal-dependent cognitive impairment in C9orf72 BAC transgenic mice
}

Nur Jury ${ }^{1,2+}$, Sebastian Abarzua ${ }^{1,2,3 \dagger}$, Ivan Diaz ${ }^{1,2}$, Miguel V. Guerra', Estibaliz Ampuero ${ }^{1,2,4}$, Paula Cubillos ${ }^{1,2}$, Pablo Martinez ${ }^{1,2}$, Andrea Herrera-Soto ${ }^{1}$, Cristian Arredondo ${ }^{1,2}$, Fabiola Rojas ${ }^{1,2}$, Marcia Manterola ${ }^{5}$, Adriana Rojas ${ }^{6}$, Martín Montecino ${ }^{1,3}$, Lorena Varela-Nallar ${ }^{1 *}$ and Brigitte van Zundert ${ }^{1,2^{*}}$ (D)

\begin{abstract}
Background: Hexanucleotide repeat expansions of the $\mathrm{G}_{4} \mathrm{C}_{2}$ motif in a non-coding region of the C9ORF72 gene are the most common genetic cause of amyotrophic lateral sclerosis (ALS) and frontotemporal dementia (FTD). Tissues from C9ALS/FTD patients and from mouse models of ALS show RNA foci, dipeptide-repeat proteins, and notably, widespread alterations in the transcriptome. Epigenetic processes regulate gene expression without changing DNA sequences and therefore could account for the altered transcriptome profiles in C9ALS/FTD; here, we explore whether the critical repressive marks H3K9me2 and H3K9me3 are altered in a recently developed C9ALS/FTD BAC mouse model (C9BAC).

Results: Chromocenters that constitute pericentric constitutive heterochromatin were visualized as DAPI- or Nucblue-dense foci in nuclei. Cultured C9BAC astrocytes exhibited a reduced staining signal for H3K9me3 (but not for H3K9me2) at chromocenters that was accompanied by a marked decline in the global nuclear level of this mark. Similar depletion of H3K9me3 at chromocenters was detected in astrocytes and neurons of the spinal cord, motor cortex, and hippocampus of C9BAC mice. The alterations of H3K9me3 in the hippocampus of C9BAC mice led us to identify previously undetected neuronal loss in CA1, CA3, and dentate gyrus, as well as hippocampal-dependent cognitive deficits.
\end{abstract}

Conclusions: Our data indicate that a loss of the repressive mark H3K9me3 in astrocytes and neurons in the central nervous system of C9BAC mice represents a signature during neurodegeneration and memory deficit of C9ALS/FTD.

Keywords: H3K9me3, ALS, FTD, Brain, Astrocyte, Neuron, Memory

\footnotetext{
* Correspondence: Iorena.varela@unab.cl; bvanzundert@unab.cl

${ }^{\dagger}$ Nur Jury and Sebastian Abarzua contributed equally to this work.

${ }^{1}$ Institute of Biomedical Sciences (ICB), Faculty of Medicine \& Faculty of Life

Sciences, Universidad Andres Bello, Santiago, Chile

Full list of author information is available at the end of the article
}

(c) The Author(s). 2020 Open Access This article is distributed under the terms of the Creative Commons Attribution 4.0 International License (http://creativecommons.org/licenses/by/4.0/), which permits unrestricted use, distribution, and reproduction in any medium, provided you give appropriate credit to the original author(s) and the source, provide a link to the Creative Commons license, and indicate if changes were made. The Creative Commons Public Domain Dedication waiver (http://creativecommons.org/publicdomain/zero/1.0/) applies to the data made available in this article, unless otherwise stated. 


\section{Background}

Amyotrophic lateral sclerosis (ALS) is a lethal disease characterized by extensive degeneration of cranial, brainstem, and spinal motoneurons in adulthood. Frontotemporal dementia (FTD) is a progressive neuronal atrophy in the frontal and temporal cortices and is characterized by progressive deficits in behavior, language, and executive function $[1,2]$. FTD is the second most common cause of early dementia ( $<65$ years), after Alzheimer's disease [3]. ALS and FTD share similar genetic signatures, including mutations in TDP-43 and C9ORF72 [3-5]. Moreover, patients harboring mutations in C9ORF72 may suffer from ALS, FTD, or a combination of the two, which explains the wide clinical diversity of the two diseases [6].

Hundreds to thousands of hexanucleotide repeat expansions of the $\mathrm{G}_{4} \mathrm{C}_{2}$ motif in a non-coding region of the C9ORF72 gene (intron 1) are now regarded as the most common genetic cause of ALS and FTD, referred to as C9ALS/FTD [7, 8]. Analyses of postmortem brain tissues of C9ALS/FTD patients, as well as of patientderived cultured cells, have led to proposed mechanisms whereby C9ORF72 repeat expansions cause the diseases; these include loss of C9ORF72 function (i.e., haploinsufficiency) and gain-of-toxicity from repeat-containing RNAs and aberrant dipeptide-repeat (DPR) proteins, through repeat-associated non-AUG-dependent (RAN) translation $[4,5,9,10]$. To elucidate the disease mechanism(s) associated with C9ALS/FTD, transgenic mice have been generated in which one or both $C 9$ orf 72 alleles were inactivated [11], or in which hundreds $(\geq 450)$ of patient-derived $\mathrm{G}_{4} \mathrm{C}_{2}$ hexanucleotide repeat expansions were expressed through bacterial artificial chromosomes (BACs) [11-14]. Unlike the C9orf72 null mice, all C9BAC mice display the molecular abnormalities that are characteristic of C9ALS/FTD patients, namely, RNA foci and DPRs, which strongly suggest that gain-oftoxicity, and not loss-of-function, is critical for C9ALS/ FTD. In addition, transcriptome analyses reveal a large number of aberrantly expressed genes (up- and downregulated) in the cortex of C9BAC mice [12] and in the cortex and hippocampus of a recent engineered mouse model expressing only proline-arginine (PR) DPRs (polyPR mice) synthesized from expanded $G_{4} C_{2}$ repeats [15] Widespread transcriptome alterations have also been found in diverse brain areas (i.e., frontal cortex, motor cortex, and cerebellum) of postmortem C9ALS/FTD patients, in induced pluripotent stem cell (iPSC)-derived neurons, and in fibroblasts derived from these patients [16-19]. Nevertheless, the mechanistic basis for these alterations has not been established. Here, we investigated whether epigenetic processes are aberrant in C9BAC mice that can account for changes in the expression profile reported in C9ALS/FTD.
Of the two major types of chromatin, euchromatin corresponds to a relaxed and transcriptionally active chromatin conformation, while heterochromatin is characterized by a condensed and transcriptionally silent organization $[20,21]$. Heterochromatin is further classified into facultative and constitutive forms. Facultative heterochromatin (fHC) comprises regions containing genes that are differentially expressed throughout development and/or differentiation and which then become silenced. Conversely, constitutive heterochromatin $(\mathrm{cHC})$ is largely formed at pericentromeres and telomeres that are gene-poor regions that mainly contain repetitive sequences, including transposable elements as well as tandemly arranged simple or satellite repeats $[20,22]$. To regulate the compaction of $\mathrm{HC}$, the nucleosomal histones in the $\mathrm{HC}$ regions are enriched by specific epigenetic marks. In particular, $\mathrm{cHC}$ is characterized by relatively high levels of the trimethylated form of lysine 9 of histone $\mathrm{H} 3$ (H3K9me3), while the $\mathrm{fHC}$ is enriched for $\mathrm{H} 3 \mathrm{~K} 9 \mathrm{me} 2$; these $\mathrm{H} 3 \mathrm{~K} 9 \mathrm{me} 2 / \mathrm{me} 3$ marks repress gene transcription, maintain genome stability (by silencing repetitive DNA elements and transposons), and protect DNA from damage [20, 21, 23-27]. Recent studies document that the distributions and/or expression levels of $\mathrm{H} 3 \mathrm{~K} 9 \mathrm{me} 2 / \mathrm{me} 3$ are altered in the brains of patients and also in models of Alzheimer's disease [26, 28-30], Huntington's disease [31], and Rett syndrome [32].

Here, we explore the nuclear distribution and expression levels of the repressive $\mathrm{H} 3 \mathrm{~K} 9 \mathrm{me} 2 / \mathrm{me} 3$ and neutral H3K9me1 marks in tissue and cultures from the recently generated mouse model C9BAC [13]. We report that the staining intensity of $\mathrm{H} 3 \mathrm{~K} 9 \mathrm{me} 3$ (but not of $\mathrm{H} 3 \mathrm{~K} 9 \mathrm{me} 2$ or H3K9me1) at chromocenters is markedly reduced in primary astrocytes from these mice. A similar reduction in H3K9me3 signal at chromocenters is observed in astrocytes and neurons in the spinal cord, motor cortex, and hippocampus of C9BAC mice. The alteration in epigenetic histone marks at C9BAC hippocampi parallels a previously undetected loss of neurons in CA1, CA3, and dentate gyrus, and a hippocampal-dependent cognitive deficit in the C9ALS/FTD mouse model. Our results suggest that the loss of $\mathrm{H} 3 \mathrm{~K} 9 \mathrm{me} 3$ plays a relevant role in the mechanistic underpinnings of neurodegeneration and cognitive deficits in C9BAC mice.

\section{Results \\ Reduced levels of nuclear $\mathrm{H} 3 \mathrm{~K} 9 \mathrm{me} 3$ in primary spinal cord astrocytes from C9BAC mice}

To explore the role of mono-, di-, and tri-methylation marks of histone $\mathrm{H} 3$ (H3K $9 \mathrm{me} 1 / \mathrm{me} 2 / \mathrm{me} 3)$ and histone modifications in the C9orf72 pathology, we first assessed the subnuclear distribution of these marks in primary cultures of spinal cord astrocytes derived from the recently engineered C9BAC mice [13]. We particularly focused on astrocytes as multiple studies have shown that 
these glial cells and astrocyte-derived conditioned media (ACM) from cultured mouse and human fALS (mutSOD1, mutTDP43, and mutC9orf72) and sALS astrocytes induce non-cell autonomous toxicity towards motoneurons by releasing soluble neurotoxic factor(s) [33-37]. In line with these studies, we found that ACM from C9BAC astrocytes also significantly reduced motoneuron survival, by $\sim 30 \%$ relative to ACM from control mice (wild-type non-transgenic littermates) (Additional file 1: Figure S1).

To evaluate the pattern of nuclear distribution and intensity of H3K9me3 mark in C9BAC and control astrocytes, we used immunostaining with a widely used commercial antibody against this modification [38-40]. Additionally, we tested the specificity of the H3K9me3 staining in N2A cells treated with chaetocin, a pharmacological inhibitor of H3K9 methyltransferase SUV39H1/2. As expected [41], a complete loss of the nuclear H3K9me3 signal was observed in cells treated with chaetocin (Additional file 1: Figure S2).

The nuclear stain DAPI was used to evaluate the global chromatin organization, particularly of the $\mathrm{cHC}$ that is located pericentrically. This region consists of very large arrays of tandemly repeating, non-coding DNA sequences termed major satellite DNA repeats. The ATrich 234-bp long major satellite repeats may extend to more than $2 \mathrm{Mb}$ per chromosome and are preferentially revealed with fluorescent DNA stains such as DAPI, TO-PRO-3, NucBlue, and Hoechst. In interphase and differentiated mouse nuclei, pericentric $\mathrm{cHC}$ clusters into large structures known as chromocenters, which are specifically marked by $\mathrm{H} 3 \mathrm{~K} 9 \mathrm{me} 3$, giving rise to H3K9me3-positive foci [20, 26, 42-44].

Confocal images showed that primary astrocytes from control mice exhibit abundant bright large $\left(\geq 0.5 \mu \mathrm{m}^{2}\right)$ H3K9me3 foci (Fig. 1a; Additional file 1: Figure S3). Astrocytes derived from C9BAC mice also displayed H3K9me3 foci; however, image analysis and quantification revealed that the mean $\mathrm{H} 3 \mathrm{~K} 9 \mathrm{me} 3$ signal intensity per nucleus was significantly reduced in C9BAC astrocytes compared with control astrocytes (Fig. 1a, b; Additional file 1: Figure S3). The reduction of the mean nuclear intensity of H3K9me3 staining in C9BAC astrocytes was due to the reduced intensity of both the foci and diffuse H3K9me3 staining (Fig. 1c, e); however, the number of H3K9me3 foci per nucleus was found unchanged (Fig. 1d), and these foci still co-localized with DAPI-chromocenters (Fig. 1e). In C9BAC astrocytes, the total number of DAPI-chromocenters (Fig. 1d) and their mean nuclear area (Fig. 1f) were similar to those found in control astrocytes; additionally, no signs of nuclear blebs were observed (Fig. 1a, c). These results indicate that the loss of H3K9me3 foci in C9BAC primary astrocytes is not accompanied by a robust loss of $\mathrm{cHC}$ or of nuclear integrity.
To determine whether the reduction in the nuclear H3K9me3 staining signal was the consequence of a redistribution or a decrease in the total amount of this repressive mark, we carried out immunoblot analysis of H3K9me3 and H3 in nuclear lysates from control and C9BAC astrocytes (Fig. 1g): we found a significant decrease in total levels of $\mathrm{H} 3 \mathrm{~K} 9 \mathrm{me} 3$ protein relative to control cells (Fig. 1h). These results indicate that the reduced $\mathrm{H} 3 \mathrm{~K} 9 \mathrm{me} 3$ signal in $\mathrm{C} 9 \mathrm{BAC}$ astrocytes involves a global loss of the repressive H3K9me3 modification.

We also analyzed H3K9me1 and H3K9me2. In contrast to the H3K9me3 pattern, the immunofluorescence signal for both marks was detected in smaller and blurrier clusters, referred to as puncta. In agreement with previous studies using the same commercial H3K9me2 antibody $[45,46]$, we found that these puncta did not co-localize with chromocenters in control or C9BAC astrocytes (Fig. 2a, b). No changes in the nuclear distribution or intensity of H3K9me1 (Fig. 2c) and H3K9me2 (Fig. 2d) were observed in C9BAC versus control astrocytes, indicating that these epigenetic marks were not affected.

\section{Nuclear H3K9me3 staining is reduced in astrocytes and neurons of the spinal cord and motor cortex from C9BAC mice}

Given the reduced levels of H3K9me3 observed in primary astrocytes, we next determined if similar epigenetic changes occur in the astrocytes and neurons of C9BAC mice. To determine the subnuclear localization of H3K9me3 in astrocytes and neurons of the spinal cord of 9-month-old C9BAC and control (non-transgenic littermates) mice, lumbar spinal cord tissue sections (L4-6) were immunostained for glial fibrillary acidic protein (GFAP) and neuronal nuclei $(\mathrm{NeuN})$ to identify astrocytes and neurons, respectively, in the dorsal and ventral spinal cord. NucBlue was used to stain DNA and to visualize chromocenters. We found that the intensity of GFAP staining signal was found increased in C9BAC spinal cord samples relative to control tissue (Fig. 3a). Confocal images (Fig. 3a, b) and quantification (Fig. 3c) revealed a significant reduction in the intensity of H3K9me3 nuclear staining in C9BAC astrocytes in L4-6 ventral spinal cord, compared with control astrocytes. The H3K9me3 signal in C9BAC mice was strictly nuclear (Fig. 3a, b), and alterations were detected neither in the NucBlue staining pattern nor in the nuclear area; mean NucBlue intensity $98 \pm 3$ and $102 \pm 4$ a.u. ( $P$ value $=0.16)$ and mean area $49 \pm 1$ and $52 \pm 2 \mu \mathrm{m}^{2}(P$ value $=$ $0.25)$ for control and C9BAC, respectively. These results show that, as observed for cultured C9BAC astrocytes, H3K9me3 is reduced in astrocytes from L4-6 spinal cord in C9BAC mice, without significant loss of $\mathrm{cHC}$ or of nuclear integrity. 


$$
\text { A }
$$
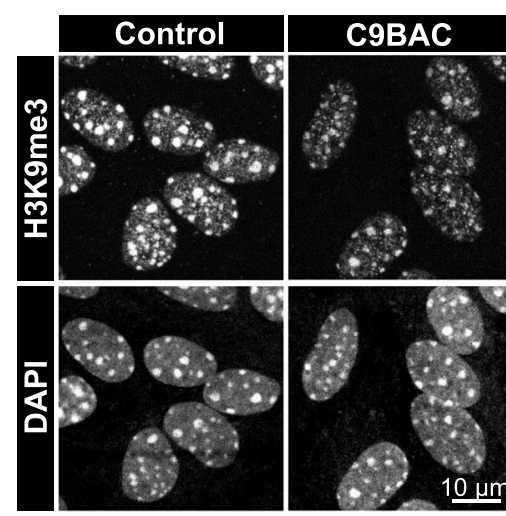

C

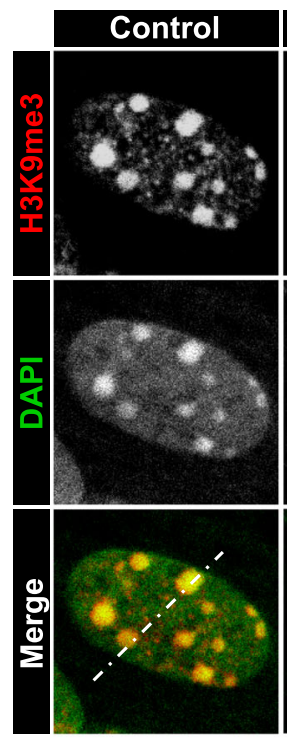

$E$

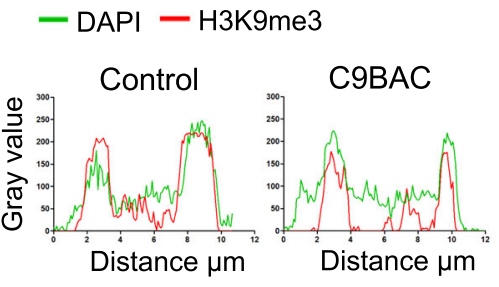

G

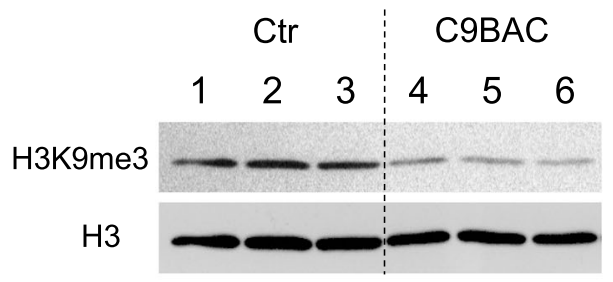

B
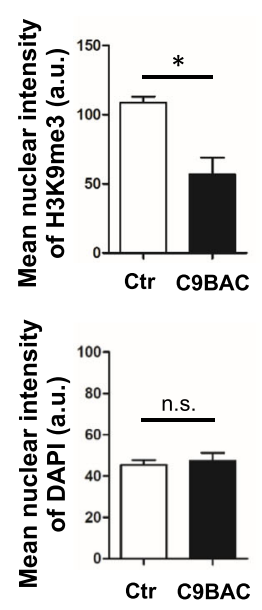

D
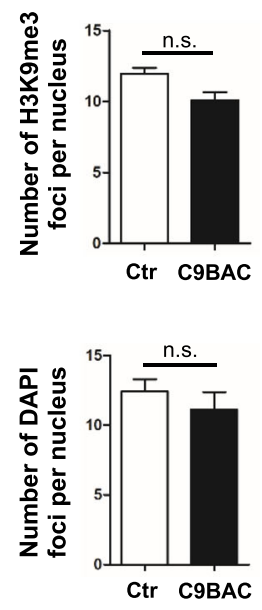

F

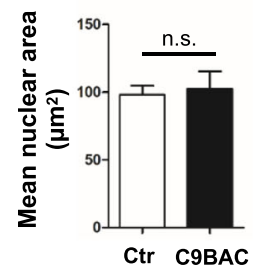

$\mathrm{H}$

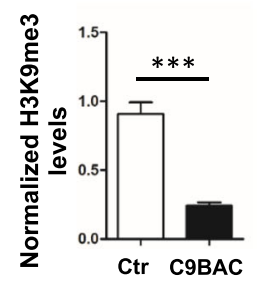


(See figure on previous page.)

Fig. 1 Reduced H3K9me3 staining at chromocenters in primary cultured astrocytes from C9BAC mice is accompanied by global loss of the H3K9me3 mark. a Representative confocal images of the immunofluorescence staining of H3K9me3 in primary cultures of control and C9BAC astrocytes. Nuclei are stained with DAPI. The images represent a maximum projection for the total nuclear volume. $\mathbf{b}$ Quantification of the mean nuclear signal staining intensity of H3K9me3 (upper graph) and DAPI (lower graph) shown as arbitrary units (a.u.). c Higher magnification of nuclei from control and C9BAC astrocytes immunostained for H3K9me3 (white and red) and stained for DAPI (white and green) are shown individually and merged. Images are single confocal sections. d Quantification of the number of H3K9me3-positive (upper graphs) and DAPIpositive foci (lower graphs) per nucleus. e Quantification of the fluorescence intensity of H3K9me3 (red) and DAPI (green) in a line scan drawn across chromocenters in nuclei from control and C9BAC astrocytes using a single confocal section. $\mathbf{f}$ Quantification of the nuclear area $\left(\mu m^{2}\right)$. In all graphs, bars represent mean \pm SEM. ${ }^{*} P<0.05$; non-statistical differences (ns), Student's $t$ test $(n=3$ independent experiments, at least 30 cells were analyzed per condition in each experiment). $\mathbf{g}$ Western blot analysis of H3K9me3 from total nuclear lysates of control (lanes 1-3) and C9BAC (lanes 4-6) astrocytes from three independent experiments are shown. H3 was used as loading control. $\mathbf{h}$ Densitometric analysis of the western blot in $\mathbf{g}$ with H3K9me3 normalized to total H3 levels. Bars represent mean \pm SEM. ${ }^{* * *} P<0.001$, Student's $t$ test

Our confocal imaging analysis also revealed prominent H3K9me3 staining in GFAP-negative cells in control mice, and the intensity of this signal was strongly reduced in tissue sections from C9BAC mice (Fig. 3a). To directly determine whether the clustered distribution of $\mathrm{H} 3 \mathrm{~K} 9 \mathrm{me} 3$ was altered in spinal cord motoneurons from C9BAC mice, we used triple fluorescence staining for $\mathrm{H} 3 \mathrm{~K} 9 \mathrm{me} 3$, NucBlue, and the neuronal marker NeuN (Fig. 3d). Ventral spinal cord sections (L4-6) from control mice showed numerous NeuN-positive motoneurons that could be readily identified due to their larger soma size $(\geq 30 \mu \mathrm{m})$ and their specific location within the spinal cord (Fig. 3d); C9BAC samples did not display evident alterations in the number or size of NeuNpositive motoneurons (Fig. 3d). These results are in agreement with the initial characterization of the C9BAC mouse model that reported the absence of behavioral changes or histological abnormalities in the motor system [13]. Similar to glial cells, the mean staining intensity of H3K9me3 was significantly reduced in the nuclei of NeuN-positive motoneurons of the C9BAC mice (Fig. 3e, f).

The staining pattern of H3K9me3 and NucBlue was markedly different in the nuclei of glial cells (Fig. 3b) versus motoneurons (Fig. $3 \mathrm{e}$ ) in the spinal cord: specifically, whereas $\mathrm{H} 3 \mathrm{~K} 9 \mathrm{me} 3$ foci and chromocenters were distributed as prominent round structures throughout the nuclei of astrocytes, H3K9me3 foci and chromocenters were concentrated at the nuclear and nucleolar periphery in control motoneurons. These H3K9me3 foci within perinuclear and/or perinucleolar chromocenters have been especially visible in highly differentiated cells, including mature neurons (i.e., [26]), mature hematopoietic cells [47], and muscle cells [48]. Despite the overall loss of $\mathrm{H} 3 \mathrm{~K} 9 \mathrm{me} 3$, the staining intensity of NucBlue (56 \pm 5 and $61 \pm 2$ a.u. for control and C9BAC, respectively with a $P$ value $=0.77)$ and the nuclear areas $\left(99 \pm 5\right.$ and $93 \pm 4 \mu^{2}$ for control and C9BAC, respectively with a $P$ value $=0.32$ ) were similar for $\mathrm{C} 9 \mathrm{BAC}$ and control motoneurons.
The staining pattern and intensity of H3K9me3 were also evaluated in sections through the motor cortex of control and C9BAC mice (Fig. 4a). Images and quantification revealed that the mean staining intensity for H3K9me3 per nucleus was significantly reduced in NeuN-positive (Fig. 4b, c) as well as NeuNnegative (Fig. 4d, e) cells in sections through the motor cortex in C9BAC mice. Loss of H3K9me3 nuclear staining in C9BAC NeuN-positive cells was not accompanied by alterations in NucBlue-chromocenter staining or in the nuclear area (mean NucBlue intensity $87 \pm 3$ and $93 \pm 3$ a.u. $(P$ value $=0.56)$ and mean area $116 \pm 3$ and $124 \pm 4$ $\mu \mathrm{m}^{2}(P$ value $=0.71)$ for control and C9BAC, respectively $)$ neither in NeuN-negative cells (mean NucBlue intensity $98 \pm 4$ and $92 \pm 3$ a.u. $(P$ value $=0.68)$ and mean area 42 \pm 2 and $44 \pm 3 \mu \mathrm{m}^{2}(P$ value $=0.28)$ for control and C9BAC, respectively). These data indicate that the reduced nuclear H3K9me3 staining is not accompanied by evidence of impairments in $\mathrm{cHC}$ or in nuclear integrity.

\section{Reduced nuclear staining of H3K9me3 in hippocampal neurons of the C9BAC mouse is accompanied by neuronal loss and OLM deficit}

While histopathology features of C9ALS/FTD (RNA foci and DPRs) are present throughout the brains of all four C9BAC mouse models [11-14], only two of these models develop hippocampal neurodegeneration [11, 14] and one exhibits spatial learning and memory deficits [11]. Here, we analyzed the nuclear staining pattern and intensity of H3K9me3 foci in hippocampal neurons using the anti-NeuN antibody (NeuN signal is not shown for easier visualization) in the C9BAC mouse model, which does not show significant hippocampal neuronal loss or phenotypic deficits [13]. Confocal images and quantification revealed that the mean intensity of $\mathrm{H} 3 \mathrm{~K} 9 \mathrm{me} 3$ staining per nucleus was strongly reduced in neurons of the DG, CA1, and CA3 in the hippocampus of 9-month-old C9BAC mice compared with control mice (Fig. 5a, b); nonetheless, these less intensely stained H3K9me3 foci remained co-localized with NucBlue-positive chromocenters (Fig. 5a). Additionally, quantification of cell density 


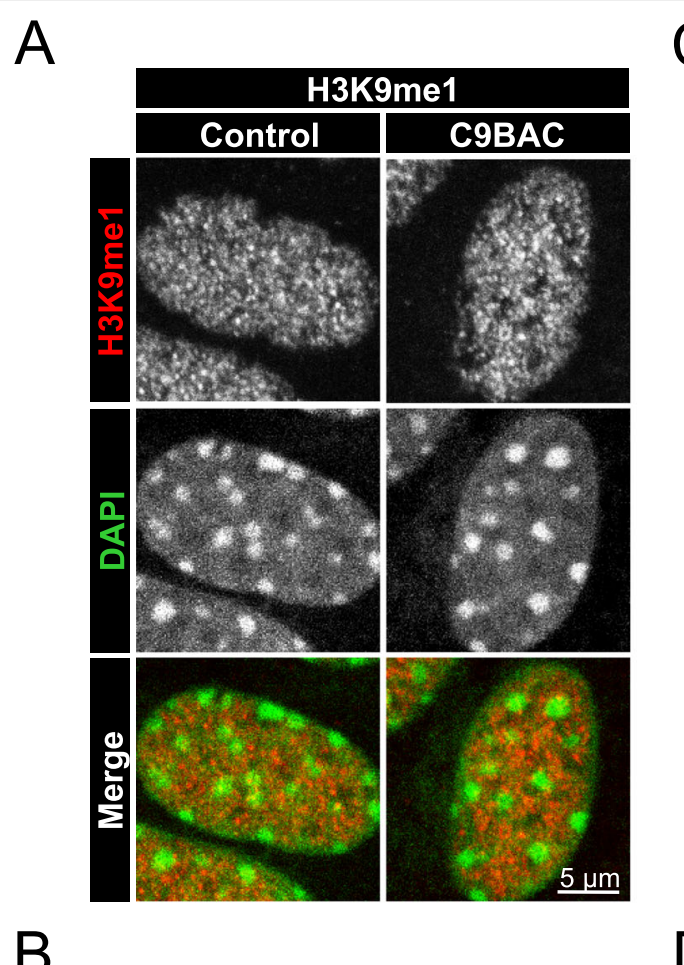

C
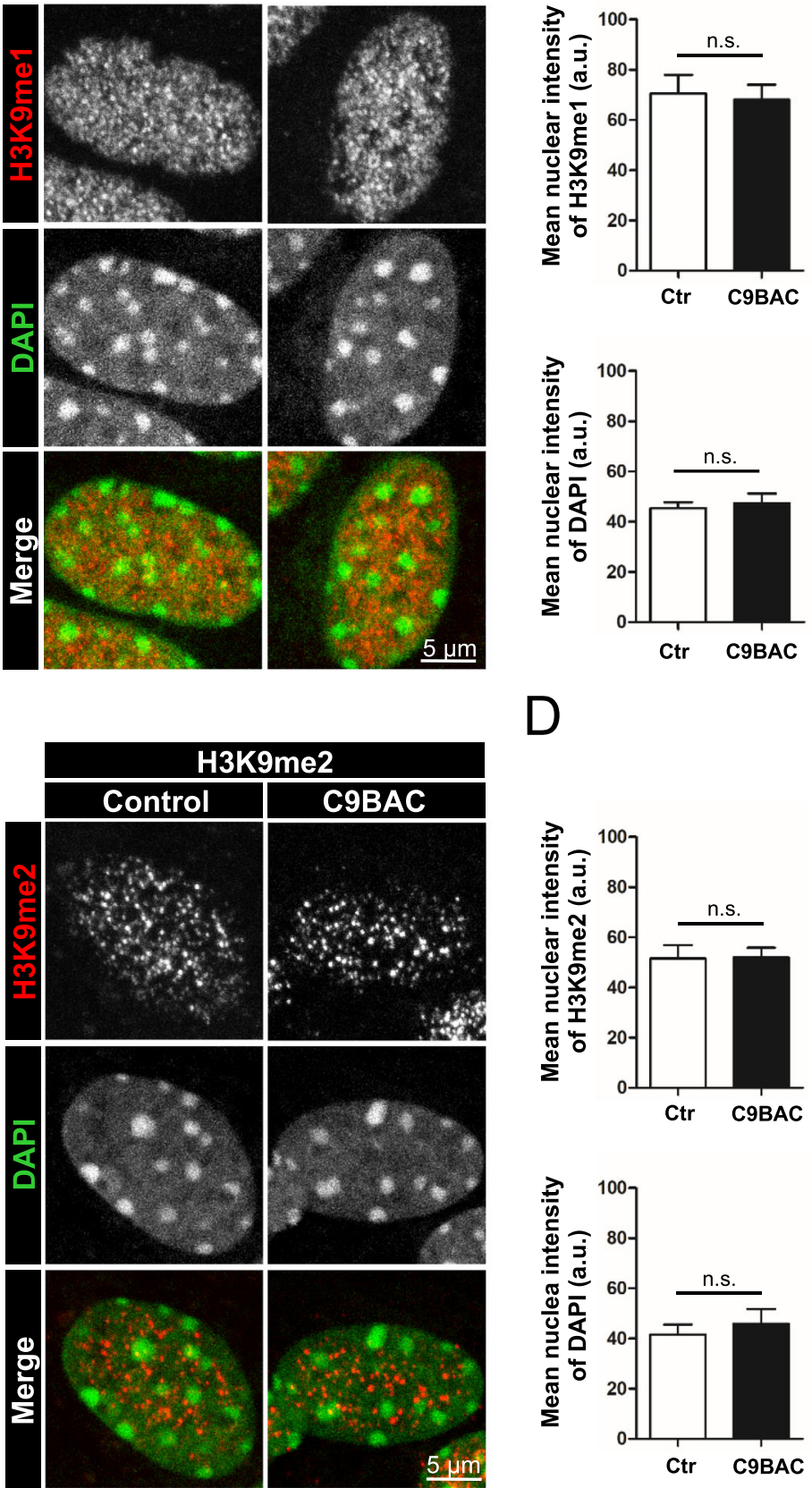

Fig. 2 The clustered distribution of H3K9me1/me2 marks is unaltered in cultured astrocytes from C9BAC mice. a, b Representative confocal images of the immunofluorescence staining of H3K9me1 ( $\mathbf{a}$, white and red) and H3K9me2 (b, white and red) in primary cultures of control and C9BAC astrocytes. Nuclei are stained with DAPI (white and green). Single confocal sections are shown. c, d Quantification of the mean nuclear intensity (a.u.) of H3K9me1 (c, upper graph) and H3K9me2 (d, upper graph) staining. Quantification of the mean nuclear intensity of DAPI (a.u.) is also shown (lower graphs). In all graphs, bars represent mean \pm SEM. Non-statistical differences (ns), Student's $t$ test $(n=3$ independent experiments, at least 30 cells were analyzed per condition in each experiment)

showed a moderate but significant neuronal loss in the CA3 region of C9BAC mice, compared with control mice (Fig. 5c).
The loss of H3K9me3 in the hippocampus in addition to the neuronal loss in CA1, CA3, and DG prompted us to explore whether the C9BAC animals also display 


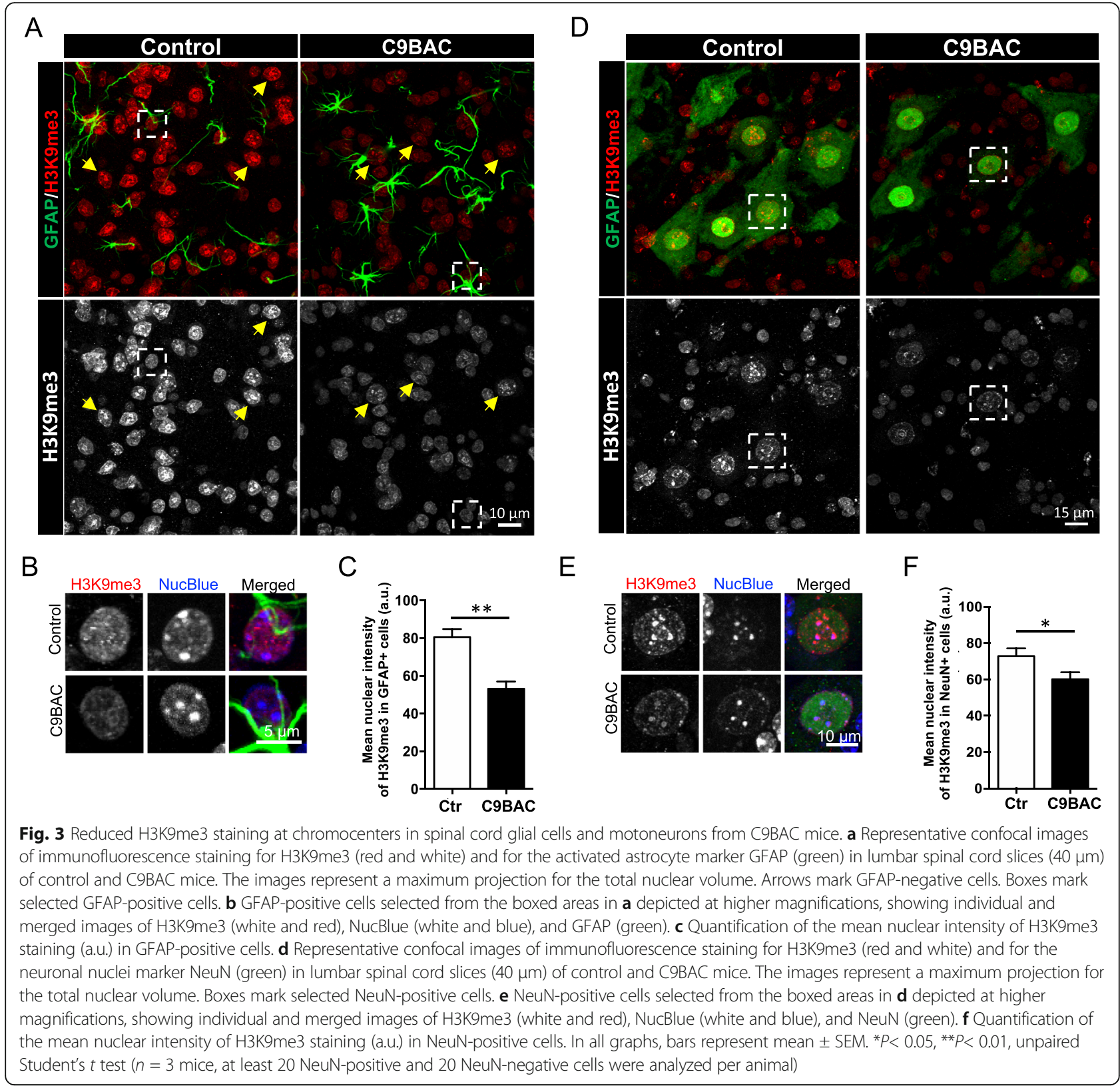

hippocampus-associated phenotypic deficits. We assessed the long-term $(24 \mathrm{~h})$ spatial memory in 6-month-old C9BAC and control mice, using the object location memory (OLM) task. OLM is a simple single-trial behavioral memory task, in which rodents are allowed to explore freely (avoiding stress) and rely on the rodent's innate preference for novelty $[49,50]$. Animals were presented with a non-displaced (ND) versus displaced (D) object in the OLM test (Fig. 5d). We found that, following $24 \mathrm{~h}$ of training, C9BAC mice performed poorly on the OLM test and displayed limited exploration of the displaced object relative to control mice (Fig. 5e, f). Together, these results show that neuronal loss and reduced H3K9me3 mark in
C9BAC mouse hippocampus neurons are accompanied by a hippocampal-dependent deficit in spatial learning and memory.

\section{Discussion}

We have used quantitative single-cell imaging to show that enrichment of $\mathrm{H} 3 \mathrm{~K} 9 \mathrm{me} 3$, the classical epigenetic silencing mark present at chromocenters, is strongly reduced in several C9BAC brain cell types, including glia and (motor) neurons in the spinal cord, as well as in the motor cortex and hippocampus. The alterations of H3K9me3 in the hippocampus of C9BAC mice led us to identify previously undetected neuronal 


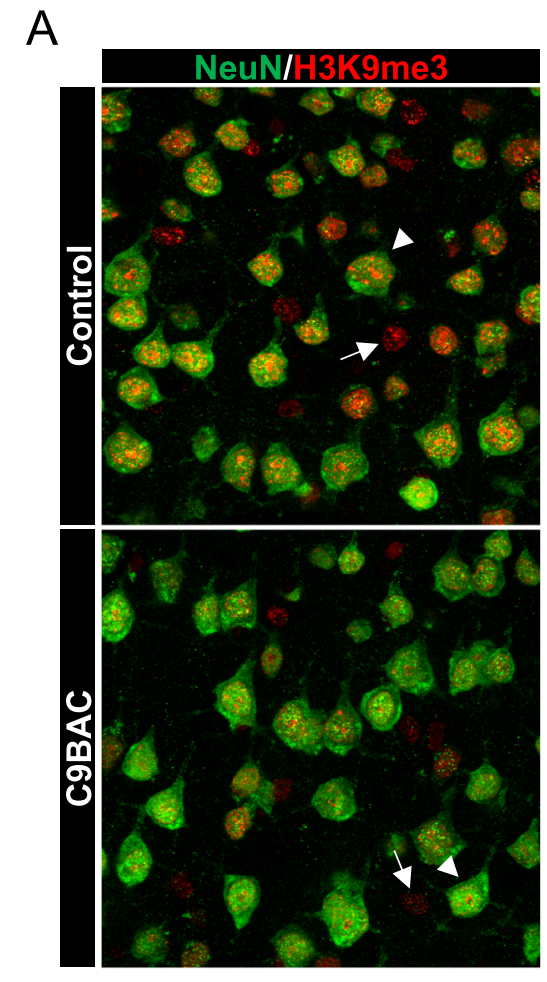

B

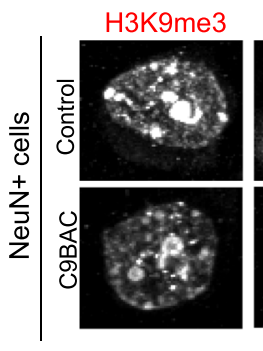

D

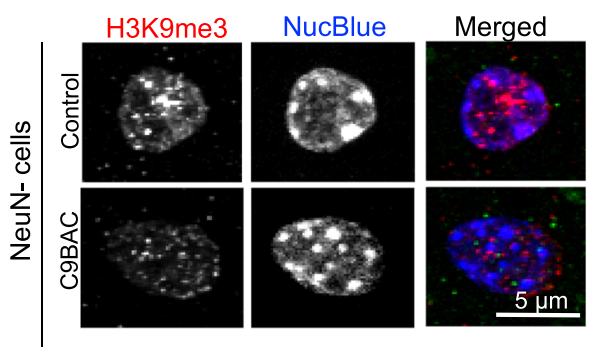

H3K9me3
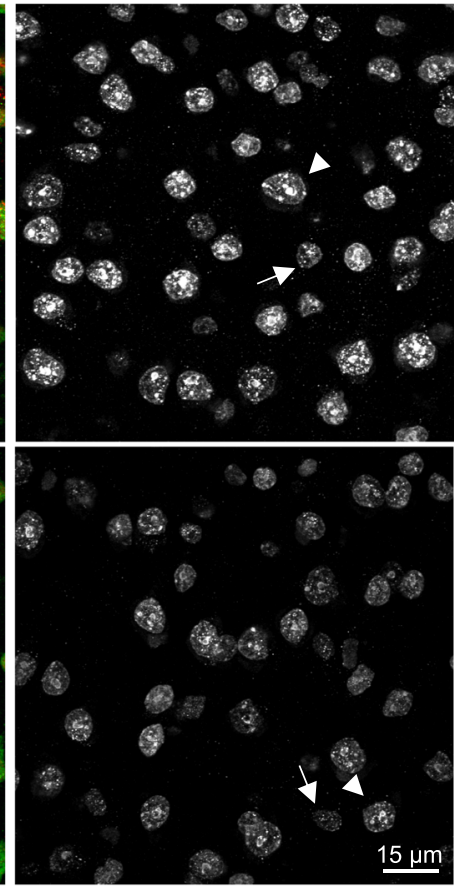

C

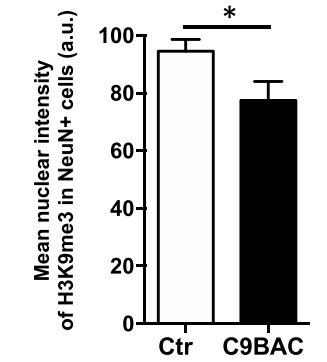

$\mathrm{E}$
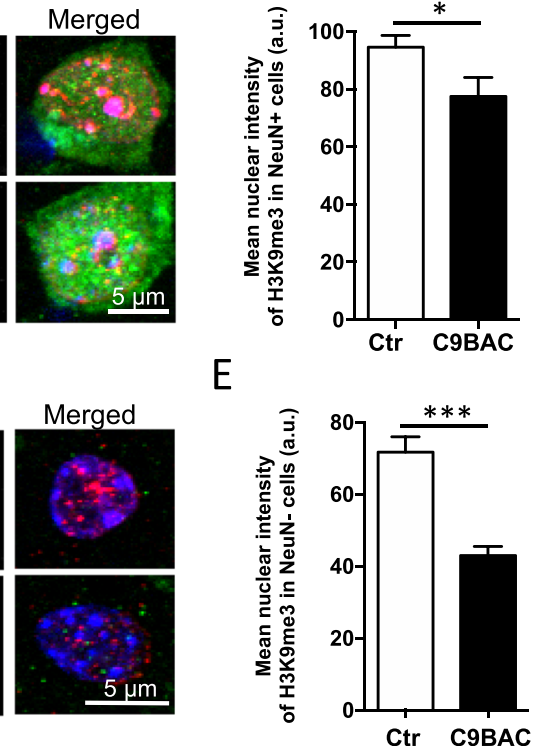

Fig. $4 \mathrm{H} 3 \mathrm{~K} 9 \mathrm{~m}$ e3 staining at chromocenters is reduced in neurons of the motor cortex in C9BAC mice. a Representative confocal images of immunofluorescence staining for H3K9me3 (red and white) and for NeuN (green) in the motor cortex from control and C9BAC mice (coronal brain section $40 \mathrm{~mm}$ ). The images represent a maximum projection for the total nuclear volume. Arrowheads indicate selected NeuN-positive cells, and arrows indicate selected NeuN-negative cells. b, d NeuN-positive (b) and NeuN-negative (d) cells selected from a depicted at higher magnifications, showing individual and merged images of H3K9me3 (white and red), NucBlue (white and blue), and NeuN (green). c, e Quantification of the mean nuclear intensity of H3K9me3 staining (a.u.) in NeuN-positive (c) and NeuN-negative (e) cells. In all graphs, bars represent mean \pm SEM. ${ }^{*} P<0.05,{ }^{* *} P<0.001$, unpaired Student's $t$ test ( $n=3$ mice, at least 25 NeuN-positive and 15 NeuN-negative cells were analyzed per animal)

loss in CA3 and to also uncover hippocampusdependent cognitive deficits. These results indicate that loss of the repressive epigenetic mark H3K9me3 is associated with neurodegeneration in the hippocampus and with corresponding cognitive impairments in the C9BAC mice. Our data, together with 


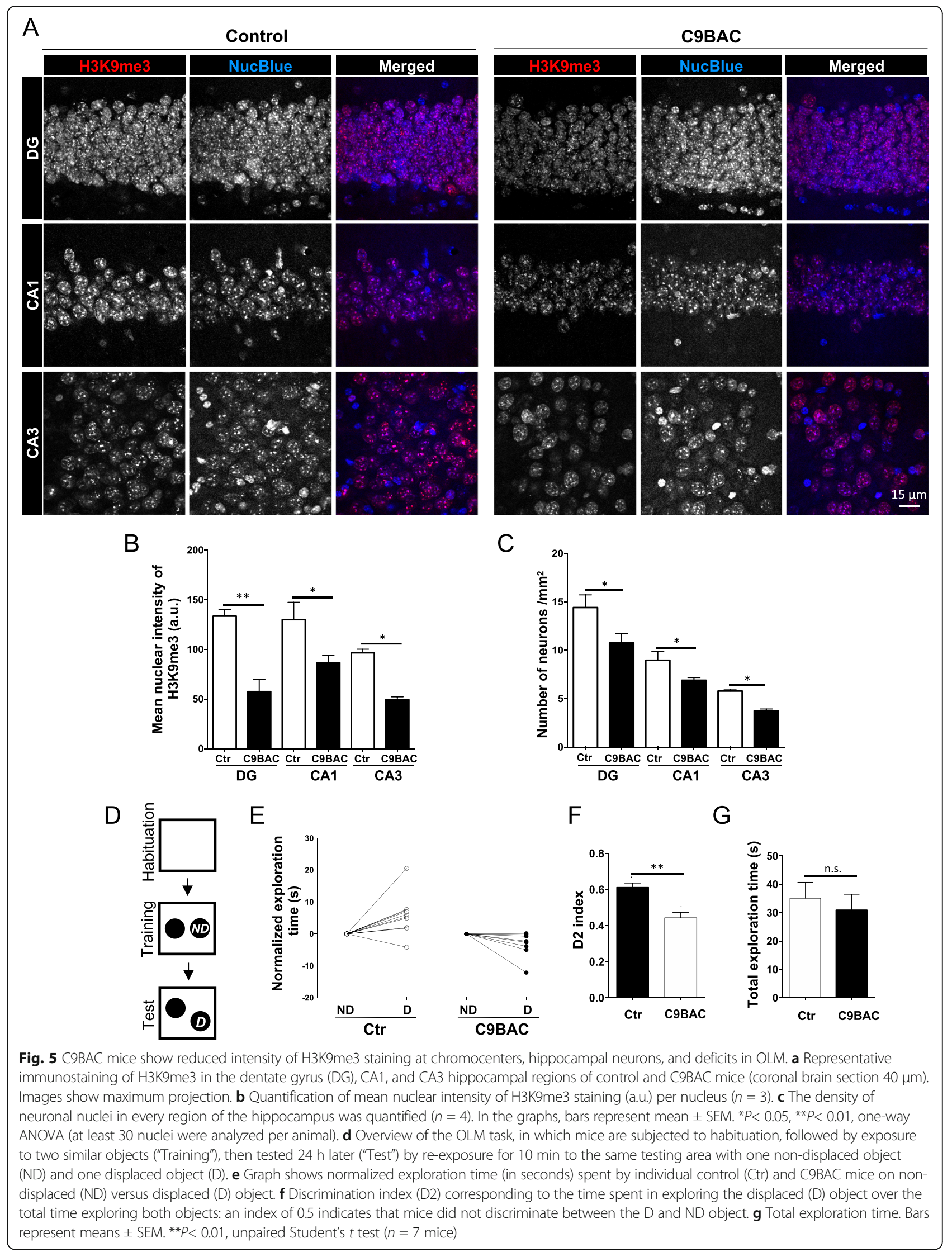


previous reports (discussed below), support a working model in which the H3K9me3 loss contributes to these pathological and behavioral alterations via aberrant gene transcription, a phenomenon that has been observed in C9ALS/FTD mouse models and patients.

To gain insights into disease mechanism(s) associated with C9ALS/FTD, several research groups have generated four C9BAC mouse models, all of which exhibit the characteristic molecular abnormalities, namely, RNA foci and DPRs, which are also observed in C9ALS/FTD patients [11-14]. Despite the consistent presence of these typical pathological features, the transgenic C9BAC mice do not all consistently develop neural loss and the clinical features found in human patients: two C9BAC mouse models exhibit neurodegeneration along with either motor [14] or cognitive and behavioral [11] deficits, but two other C9BAC mouse models do not display significant neuronal loss or phenotypic features $[12,13]$. The reasons for these contrasting results are not known [51], but careful analyses and comparison of the different C9BAC models may help unraveling the molecular mechanisms that underlie the pathogenesis and phenotype of C9ALS/FTD. Here, for example, the moderate and region-specific neuronal loss (in CA3 but not in CA1 and DG) and in behavioral alterations (OLM) in the "non-symptomatic" C9BAC mouse model [13] were only detected because we analyzed the hippocampus in greater detail and uncovered a significantly reduced H3K9me3 nuclear staining. Our data show that C9BAC mice developed hippocampal neural loss and cognitive deficits without motor-associated deficits, suggesting that this mouse model recapitulates mild phenotypic features of FTD.

Here, we document that nuclear H3K9me3 staining is largely reduced in C9BAC astrocytes and neurons. Similar quantitative single-cell imaging studies of neurons in tissue derived from patients as well as in tau models of Alzheimer's disease indicate a strong reduced nuclear signal for H3K9me3 [26] and H3K9me2 [28, 29]. Additional analysis by Mansuroglu and colleagues [26] revealed that reduced $\mathrm{H} 3 \mathrm{~K} 9 \mathrm{me} 3$ labeling in neuronal nuclei from Alzheimer's disease is accompanied by a strong presence of this mark in the cytoplasm. Hoechst staining showed that the structure of chromocenters in Alzheimer's disease neurons is disrupted. In our study, however, imaging assays do not indicate that in C9BAC cells the H3K9me3 mark is redistributed from the nucleus to the cytoplasm or that $\mathrm{cHC}$ and nuclear integrity is compromised.

We also evaluated another brain region (striatum) and peripheral tissues (liver and testis) and observed no changes in H3K9me3 staining (Additional file 1: Figure S4-5). All the cells analyzed in the present study (i.e., astrocytes, neurons, hepatocytes, and Sertoli cells) exhibit different heterochromatin features as evidenced by the DAPI/NucBlue staining. Based on these results, we suggest that the loss of H3K9me3 is more likely associated to specific brain regions (cortex and hippocampus) rather than to the heterochromatin structure.

Our imaging and biochemical assays show that C9BAC astrocytes exhibit a strong decrease in total nuclear H3K9me3 levels and in H3K9me3 enrichment at chromocenters compared to that in control astrocytes. Interestingly, immunostaining analysis in poly-PR mice showed that GFP-conjugated PR protein (a 50 repeat PR protein) localized to the H3K9me3, H3K27me3, and H3K4me3 marks; the latter two marks were also increased in GFP-PR-positive cells [15]. Recent investigations using cell lines suggest that the expression of SOD1 and TDP43 could also contribute to global epigenome alterations [52]. These findings point to a need for further in-depth analysis of H3K9me3 alterations in brain cells expressing mutant C9orf72, SOD1, and TDP43. Despite these findings, we found that C9BAC astrocytes exhibit a strong decrease in total nuclear H3K9me3 levels. Esanov and collaborators, using of ChIP-qPCR assays on the same C9BAC mouse model, documented that $\mathrm{H} 3 \mathrm{~K} 9 \mathrm{me} 3$ enrichment at the human C9ORF72 gene promoter is significantly increased [53]. Other ChIP-qPCR assays, together with bisulfide sequencing of the expanded C9ORF72 locus, performed on tissue and cells derived from C9-ALS/FTD patients, also show that the local epigenetic status is significantly altered, with an enrichment of the repressive H3K9me3 and H3K27me3 marks as well as DNA methylation [53-57]. These data collectively indicate that while C9BAC expressing cells exhibit a strong decrease in total nuclear H3K9me3 levels in astrocytes and neurons, at least some of the remaining $\mathrm{H} 3 \mathrm{~K} 9 \mathrm{me} 3$ mark may be redistributed within the genome and be deposited at specific genes such as C9ORF72. The increased epigenetic silencing of the mutant C9ORF72 allele by DNA hypermethylation and $\mathrm{H} 3 \mathrm{~K} 9 \mathrm{me} 3$ is believed to protect neurons from the burden of the pathology associated with the repeat-expansion [54, $58,59]$. Based on these results, we speculate that an additional loss of nuclear H3K9me3 levels, due for example to aging or environmental factors, could jeopardize H3K9me3 enrichment on the mutant C9ORF72 allele, and thereby facilitate and increase in the repeat-expansion expression associated with this pathology.

What are the functional consequences of a lower level of H3K9me3 in C9BAC brain cells? ChIP assays have documented H3K9me3 enrichment at transcriptionally silent protein coding genes in both heterochromatic and active euchromatic regions [50,60-63]. These data indicate that reduced H3K9me3 in C9BAC cells might result in increased expression of genes, if other epigenetic mechanisms, such as DNA methylation, exchange of histone variants, nucleosome remodeling, and/or long 
non-coding RNAs, do not counterbalance the loss of the repressive histone mark. Whether such compensatory epigenetic mechanisms occur is presently unknown. However, if so, they appear to be insufficient at coding genes as widespread alterations in mRNA expression have been detected in the transcriptome of brain tissue [19], skin biopsy-derived fibroblasts [16, 17], and iPSCs $[16,18]$ from C9orf72 patients as well as in the spinal cord and cortex from C9BAC mice [12]. Lower levels of $\mathrm{H} 3 \mathrm{~K} 9 \mathrm{me} 3$ at $\mathrm{cHC}$ regions could also have important deleterious consequences, as determined from studies of mice that are knockout for H3K9 methyl transferases. For example, Suv39h1/2-deficient mice display severely reduced viability, chromosomal instability (presence of hyper-tetraploid number of chromosomes), and higher levels of major satellite repeat transcripts that underlie the pericentromeric $\mathrm{cHC}$ regions $[43,44]$. Furthermore, lower levels of H3K9me3 in C9BAC brain cells could influence the chromatin organization and gene expression of large continuous genomic regions that associate tridimensionally with chromocenters inside the nucleus [64]. That is, pericentromeric $\mathrm{cHC}$ regions have local chromatin interactions identified by $\mathrm{Hi}-\mathrm{C}$ with other genomic regions that are sufficient to induce $\mathrm{H} 3 \mathrm{~K} 9 \mathrm{me} 3$ deposition and to contribute to the repression of associated genes. Therefore, a decrease in H3K9me3 levels (in the absence of compensatory epigenetic mechanisms such as DNA methylation) could influence coding and noncoding gene expression in a trans and cis manner. Notably, evidence for aberrant expression of coding and non-coding genes, including repeat elements, has been reported in patients and in tau animal models of $\mathrm{AD}$ $[28,29,65]$ that also display reduced H3K9me3 [26] or H3K9me2 staining signals [28, 29]. Interestingly, abnormal expression of repeat elements has also been reported in poly-PR mice [15]. Additional ChIP and transcriptomic analyses of C9BAC mice should establish whether aberrant coding and non-coding gene expression are associated with the depletion of H3K9me3 at specific genomic regions.

\section{Methods}

\section{Animals}

All protocols involving mice were carried out according to NIH guidelines and ARRIVE guidelines and were approved by the Ethical and Bio-security Committees of Universidad Andrés Bello. Transgenic mice line expressing a familial ALS/FTD human patient-derived C9orf72 genomic DNA sequence (C9BAC) [13] was a kind gift of Dr. Robert Brown (University of Massachusetts Medical School, Worcester) and B6SJLF/J mice were used as control subjects. Transgenes in the C9BAC mice were identified by PCR using the primers for Orf72e3: forward 5' TTA ATT TCC TAC CCC TGC CC 3' and reverse 5'
AGG CCT TGA CAA ATG TAG CC 3' and for Mm10chr3: forward 5' GCC TCA CCt CCT AAG AGC CTA 3' and reverse 5' CCT TTG TGT CAC ACG GAT ATC 3' [13].

\section{Primary mouse spinal cord astrocytes and ACM preparation}

The primary mouse spinal cord astrocyte cultures were generated from individual whole spinal cords of P1-2 wild-type mice and transgenic C9BAC mice, and PCR (see above) of tail tissue of each neonatal mouse was performed to define whether the astrocytes were from wild-type mice (Ctr) or transgenic C9BAC mice, as previously described $[33,34,66]$. Briefly, spinal cords were excised, minced, and enzymatically treated by incubating in pre-warmed PBS containing $0.25 \%$ trypsin (Gibco, Cat. No. 15090-046) for $20 \mathrm{~min}$ at $37{ }^{\circ} \mathrm{C}$. Cells were maintained in DMEM (Hyclone, Cat. No. SH30081.01) containing 10\% FBS (Gibco, Cat. No. 16000-044), 1\% Lglutamine (Gibco, Cat. No. 25030-081), and 1\% penicillin-streptomycin (Gibco, Cat. No. 15140-122) at $37^{\circ} \mathrm{C}$ $5 \% \mathrm{CO}_{2}$. Cultures reached confluence after 2-3 weeks and contained $>95 \%$ GFAP+ astrocytes. Residual microglia were removed by shaking cultures in an orbital shaker (200 rpm in the incubator) overnight, at which point media was replaced by neuronal growth media, including 70\% MEM (Gibco, Cat. No. 11090-073), 25\% Neurobasal media (Gibco, Cat. No. 21103-049), 1\% N2 supplement (Gibco, Cat. No. 17502-048), 1\% L-glutamine (Gibco, Cat. No. 25030-081), 1\% penicillin-streptomycin (Gibco, Cat. No. 15140-122), 2\% horse serum (Gibco, Cat. No. 15060-114; lot 1517711), and 1\% sodium pyruvate (Gibco, Cat. No. 11360-070). After 7 days, ACM was collected, supplemented with $4.5 \mathrm{mg} \mathrm{ml}^{-1}$ D-glucose (final concentration), and filtered and stored at $-80{ }^{\circ} \mathrm{C}$. These media were used to evaluate survival of motoneurons in primary ventral spinal neuronal cultures prepared from Sprague-Dawley rats at E14 [33, 34, 66].

\section{Immunostaining}

The whole immunostaining process, including the incubation with the specific antibodies, was always carried out in parallel in both control and C9orf72 cells/tissues. Paraformaldehyde-fixed cultured astrocytes, brain tissue sections, testicular cells, and liver hepatocytes from control and C9BAC mice were used for immunostaining experiments. Astrocyte cultures (see above) were fixed with fresh $4 \%$ paraformaldehyde for $20 \mathrm{~min}$, permeabilized with $0.1 \%$ Triton X-100 in PBS for 20 min, and incubated with normal goat serum (10\%) blocking solution (Invitrogen, 50062Z) for $30 \mathrm{~min}$. Brain tissue sections were incubated with blocking/permeabilization solution (3\% donkey serum and 3\% BSA in $0.5 \%$ Triton X-100 in PBS) for $4 \mathrm{~h}$. For tissue sectioning, the brain and spinal cord were 
carefully removed from transcardially perfused mice and immersed in $4 \%$ paraformaldehyde overnight. Samples were cryoprotected in 30\% sucrose and sliced sagittally (40 $\mu \mathrm{m}$ thick) using a cryostat (Leica CM1520). Testicular cells were obtained by performing cellular spreads isolating the seminiferous tubules and mechanically disaggregating using forceps. Then, $200 \mu \mathrm{l}$ of $100-\mathrm{mM}$ sucrose was slowly added and mixed with the cells. From this suspension, $14 \mu \mathrm{l}$ was dropped onto a slide previously submerged in $1 \%$ paraformaldehyde (PFA), $\mathrm{pH}$ 9.2, and spread throughout the slide. Next, the slides were slowly dried in a humid chamber for $3 \mathrm{~h}$, washed with Photo-Flo $0.08 \%$ in distilled water, air-dried, and stored at $-80{ }^{\circ} \mathrm{C}$ until their use. Sertoli cells were identified and classified based on the nuclear morphology (nuclear size and shape, as well as localization, distribution, and size of the chromocenters) observed with DAPI staining [67]. Liver hepatocytes were obtained by imprint cytology. Briefly, 4\% paraformaldehyde-fixed liver was freshly cut, and liver imprints were made by gently touching the cut surface of the node onto a glass slide.

Cells and tissue sections were incubated overnight at $4{ }^{\circ} \mathrm{C}$ with primary antibodies: H3K9me3 (Abcam, USA Cat. No. ab8898, 1:1,000, rabbit), H3K9me2 (Abcam, USA, Cat. No. ab1220, 1:500, mouse), H3K9me1 (Abcam, USA, Cat. No. ab9045, 1:1000, rabbit), NeuN (Millipore, USA, Cat. No. MAB377, 1:300, mouse), and GFAP (DAKO, USA, Cat. No. Z0334, 1:1,000, rabbit). After rinsing three times with 0.5\% Triton X-100 in PBS, cells and tissue samples were incubated with Alexa-conjugated secondary antibodies [Alexa Fluor $488\left(\right.$ Alexa $^{488}$ ) or 546 (Alexa ${ }^{546}$ ), Invitrogen, USA] for $1 \mathrm{~h}$ at room temperature. ProLong Gold Antifade Mountant with DAPI (Thermo Fisher, Cat. No. P36931) or NucBlue (Invitrogen, Cat. No. R37605) were used to stain the nucleus in cells and in tissue sections, respectively.

Acquisition settings were always the same for the specific cell types, and acquisition was carried out in parallel in both control and C9orf72 cells/tissues. Images of primary astrocytes were taken on a Leica TCS SP8 confocal microscope with a $\times 63$ oil objective and $\times 2$ digital zoom (NA $=1.4$; HC PL ACS APO) and a z-step of 0.5$\mu \mathrm{m}$ optical sections (velocity scan $600 \mathrm{~Hz}$; resolution $1024 \times 1024$ pixels, equivalent to $87.3 \mu \mathrm{m} \times 87.3 \mu \mathrm{m}$ ). The following laser wavelengths were used to detect DAPI (Ex $405 \mathrm{~nm}$ and Em 410-483 nm) and HPTMsAlexa $^{546}$ (Ex $561 \mathrm{~nm}$ and Em 570-625 nm). Maximum intensity projections of confocal z-stack images of whole nuclei (containing 10-12 stacks) were analyzed. Images of brain tissue sections were taken on an Olympus FV1000 confocal microscope with a $\times 60$ oil objective $(\mathrm{NA}=1.35$; UPLSAPO $)$ and a z-step of $0.5-\mu \mathrm{m}$ optical sections (velocity scan $12 \mu \mathrm{s} /$ pixel; resolution $1024 \times$ 1024 pixels, equivalent to $211.761 \mu \mathrm{m} \times 211.761 \mu \mathrm{m}$ ). The following laser wavelengths were used to detect
NucBlue (Ex $405 \mathrm{~nm}$ and Em 422-475 nm), cell type marker-Alexa ${ }^{488}$ (Ex $488 \mathrm{~nm}$ and Em 500-530 nm) and HPTMs-Alexa ${ }^{546}$ (Ex $543 \mathrm{~nm}$ and Em BA560-660 nm). Maximum intensity projections of confocal z-stack images of whole nuclei (containing 5-7 stacks in the spinal cord, 15-20 stack in the motor cortex, and 5-7 stacks in the hippocampus) were analyzed. Images of testicular cells and hepatocytes were obtained using a Nikon Eclipse E400 epifluorescence microscope equipped with an Infinity 5 camera. For these cell types, all the pictures were taken using a $\times 100$ magnification lens.

The Fiji ImageJ software $(8$ bits, measuring intensity from 0 to 255) was used to measure the DAPI/NucBlue and H3K9me3 fluorescence intensity and mean nuclear area. Line scans were drawn in ImageJ to quantify the relative intensities of the fluorescence signal for DAPI and H3K9me3. The quantification of foci $(\geq 0.50 \mu \mathrm{m})$ was carried out under threshold conditions using the analyze particle plugin. Maximum intensity projections of confocal z-stack images of whole nuclei were analyzed. At least 20 isolated nuclei were analyzed for each cell type (astrocytes, neurons, hepatocytes, and Sertoli cells). The number of neurons in hippocampal DG, CA1, and CA3 regions was counted as previously described [11] in 2-3 consecutive sections. Careful matching of the sections to compare similar anatomical regions was performed for each set of mice.

\section{Western blotting}

Cultured astrocytes from control and C9BAC mice were lysed in an ice-cold lysis buffer $[60 \mathrm{mM} \mathrm{KCl}, 15 \mathrm{mM}$ $\mathrm{NaCl}, 2 \mathrm{mM}$ EDTA, $0.5 \mathrm{mM}$ EGTA, $15 \mathrm{mM}$ Tris- $\mathrm{HCl}$ $\mathrm{pH}$ 7.4, $0.5 \mathrm{mM}$ spermidine (Sigma-Aldrich, Cat. No. S2501), $0.5 \mathrm{mM}$ DTT, and 0.2\% nonidet NP-40]. Using the Kimble Dounce tissue grinder set (Sigma D8938), the membrane was disintegrated to obtain isolated nuclear fractions. The pellet was resuspended in a sonication buffer [50 mM HEPES pH 7.9, $140 \mathrm{mM} \mathrm{NaCl}, 1$ mM EDTA, 1\% Triton X-100, $0.1 \%$ sodium deoxycholate, and 10\% SDS with protease inhibitors (Roche, Cat. No. 11836153001)] and sonication was performed by a Bioruptor (Diagenode) for $5 \mathrm{~min}$ at maximum power. Protein samples $(10-20 \mu \mathrm{g})$ were resolved by $10 \%$ SDS-PAGE, transferred to a nitrocellulose membrane, blocked with $5 \%$ milk in PBS-Tween 20 $0.1 \%$ (TPBS), and incubated overnight at $4{ }^{\circ} \mathrm{C}$ with rabbit anti-H3K9me3 (Abcam, USA Cat. No. ab8898, 1:1,000). After washing, the membrane was incubated with HRPconjugated secondary antibody (Santa Cruz Biotechnology, 1:5,000) and developed using the ECL plus western blotting detection reagent from Thermo Scientific (Rockford, IL, USA). Then, for the detection of total H3, the same membrane was incubated with the ReBlot Plus Strong Antibody Stripping Solution (Millipore, Cat. No. 2504) for $3 \mathrm{~min}$. After washing three times with $0.05 \%$ Tween, the 
membrane was blocked with 5\% milk in TPBS for 30 min incubated overnight at $4{ }^{\circ} \mathrm{C}$ with mouse anti-H3 pan (Diagenode, Cat No. C15200011, 1:10000) and then incubated with HRP-conjugated secondary antibody (Santa Cruz Biotechnology, 1:5,000) and developed using the ECL technique. Densitometric analysis was performed using the ImageJ software. H3K9me3 was normalized to total $\mathrm{H} 3$ levels.

\section{Object location memory (OLM)}

The OLM test was performed as previously described [50]. Briefly, the single trail OLM test consisted of three steps: habituation $(5 \mathrm{~min})$, a training session $(10 \mathrm{~min})$, and a test session $(10 \mathrm{~min}) 24 \mathrm{~h}$ later. Mice were individually habituated in an apparatus that contained a cage inside an insonorized chamber. In the training session, the cage contained two identical objects, termed "nonedisplaced objects" (ND). In the test session, the location of one of the none-displaced objects was changed, termed displaced object (D). The exploration time was recorded and defined as time spent sniffing or touching the object with the nose and/or forepaws. The "discrimination index" was calculated by the time spent to explore object ND compared with total time explored in both objects (D + ND).

\section{Statistical analyses}

Statistical analysis was performed using an unpaired Student's $t$ test (normal data) and a Mann-Whitney test when two populations were examined. A oneway ANOVA followed by the Bonferroni post hoc was utilized when making multiple comparisons. In all figures, error bars represent the SEM, ${ }^{*} P<0.05$, ** $P<0.01$, **** $P<0.001$.

\section{Supplementary information}

Supplementary information accompanies this paper at https://doi.org/10. 1186/s13148-020-0816-9.

Additional file 1: Figure S1. ACM derived from C9BAC astrocytes significantly reduces motoneuron survival. Figure S2. Loss of H3K9me3 staining in N2A cells treated with chaetocin. Figure S3. H3K9me3 staining overview in primary astrocytes cultured reveals global reduction of $\mathrm{H} 3 \mathrm{~K} 9 \mathrm{me} 3$ fluorescence intensity. Figure S4. H3K9me3 staining in striatal neurons from C9BAC and control mice. Figure S5. H3K9me3 staining in hepatocytes and Sertoli cells from C9BAC and control mice.

\footnotetext{
Abbreviations

ACM: Astrocyte-derived conditioned media; ALS: Amyotrophic lateral sclerosis; BAC: Bacterial artificial chromosome; BSA: Bovine serum albumin; C9BAC: C9ALS/FTD BAC mouse model; CA: Cornu ammonis; CHC: Constitutive heterochromatin; D: Displaced; DG: Dentate gyrus; DPR: Dipeptide-repeat; FBS: Fetal bovine serum; fHC: Facultative heterochromatin; FTD: Frontotemporal dementia; GFAP: Glial fibrillary acidic protein; iPSC: Induced pluripotent stem cell; ND: Non-displaced; NeuN: Neuronal nuclei; OLM: Object location memory; PR: Proline-arginine; RAN: Repeat-associated non-AUG-dependent
}

\section{Acknowledgements}

We thank Dr. Sonal Jhaveri for her professional editing service.

\section{Authors' contributions}

$\mathrm{NJ}, \mathrm{SA}, \mathrm{MMa}, \mathrm{AR}, \mathrm{MMo}, \mathrm{LV}-\mathrm{N}$, and BVZ designed the experiments to determine H3K9me1/2/3 levels by staining assays and western blot assays in mouse cultures and brain tissues. EA, PC, LV-N, and BVZ designed the behavioral studies. $C A$ and $B V Z$ designed the experiments to determine motoneuron toxicity by astrocyte-conditioned media. NJ, SA, LV-N, and BVZ wrote the paper. All authors reviewed and edited the manuscript. SA and PM performed experiments to

determine H3K9me1/2/3 levels by staining assays and western blot assays in mouse cultures. $\mathrm{NJ}, \mathrm{ID}, \mathrm{MG}$, and $\mathrm{AH}$-S performed immunofluorescence experiments to determine $\mathrm{H} 3 \mathrm{~K} 9 \mathrm{me} 1 / 2 / 3$ distribution and levels in spinal cord and brain tissues. CA and FR performed astrocyte-conditioned media toxicity assays. All authors read and approved the final manuscript.

\section{Funding}

Grants from FONDECYT (1181645, BVZ; 1190461, LVN), CONICYT PIA/BASAL (AFB 170005 CARE UC, BVZ), The ALS Association 20-DDC-497 (BVZ), FightMND (BvZ), Nucleus UNAB (DI-4-17/N, BVZ, LVN); FONDAP (15090007, MMo), CONICYT (201161486, NJ; 21151265, SA; 21151563, PM), and FBR 4171-PUJ8253 (AR)

\section{Availability of data and materials}

All data generated or analyzed during this study are included in this published article.

\section{Ethics approval and consent to participate}

All protocols involving rodents were carried out according to the $\mathrm{NIH}$ and ARRIVE guidelines and were approved by the Ethical and Bio-security

Committees of Andrés Bello University.

\section{Consent for publication}

Not applicable.

\section{Competing interests}

The authors declare that they have no competing interests.

\section{Author details}

${ }^{1}$ Institute of Biomedical Sciences (ICB), Faculty of Medicine \& Faculty of Life Sciences, Universidad Andres Bello, Santiago, Chile. ${ }^{2}$ CARE Biomedical Research Center, Faculty of Biological Sciences, Pontificia Universidad Católica de Chile, Santiago, Chile. ${ }^{3}$ FONDAP Center for Genome Regulation, Santiago, Chile. ${ }^{4}$ Current address: Faculty of Health Sciences, Universidad Autónoma de Chile, Santiago, Chile. ${ }^{5}$ Program of Human Genetics, ICBM, Faculty of Medicine, Universidad de Chile, Santiago, Chile. ${ }^{6}$ Instituto de Genética Humana, Pontificia Universidad Javeriana, Bogotá, Colombia.

Received: 31 October 2019 Accepted: 23 January 2020

Published online: 18 February 2020

\section{References}

1. McKhann GM, Albert MS, Grossman M, Miller B, Dickson D, Trojanowski JQ, et al. Clinical and pathological diagnosis of frontotemporal dementia: report of the Work Group on Frontotemporal Dementia and Pick's Disease. Arch Neurol. 2001;58(11):1803-9.

2. Neary D, Snowden J, Mann D. Frontotemporal dementia. Lancet Neurol. 2005;4(11):771-80

3. Van Langenhove T, van der Zee J, Van Broeckhoven C. The molecular basis of the frontotemporal lobar degeneration-amyotrophic lateral sclerosis spectrum. Ann Med. 2012;44(8):817-28.

4. Ling SC, Polymenidou M, Cleveland DW. Converging mechanisms in ALS and FTD: disrupted RNA and protein homeostasis. Neuron. 2013;79(3):41638.

5. Taylor JP, Brown RH Jr, Cleveland DW. Decoding ALS: from genes to mechanism. Nature. 2016:539(7628):197-206.

6. Yokoyama JS, Sirkis DW, Miller BL. C9ORF72 hexanucleotide repeats in behavioral and motor neuron disease: clinical heterogeneity and pathological diversity. Am J Neurodegener Dis. 2014;3(1):1-18.

7. DeJesus-Hernandez M, Mackenzie IR, Boeve BF, Boxer AL, Baker M, Rutherford NJ, et al. Expanded GGGGCC hexanucleotide repeat in 
noncoding region of C9ORF72 causes chromosome 9p-linked FTD and ALS. Neuron. 2011;72(2):245-56.

8. Renton AE, Majounie E, Waite A, Simón-Sánchez J, Rollinson S, Gibbs JR, et al. A hexanucleotide repeat expansion in C9ORF72 is the cause of chromosome 9p21linked ALS-FTD. Neuron. 2011;72(2):257-68.

9. Gendron TF, Bieniek KF, Zhang YJ, Jansen-West K, Ash PE, Caulfield T, et al. Antisense transcripts of the expanded C9ORF72 hexanucleotide repeat form nuclear RNA foci and undergo repeat-associated non-ATG translation in C9FID/ALS. Acta Neuropathol. 2013;126(6):829-44.

10. Wen X, Tan W, Westergard T, Krishnamurthy K, Markandaiah SS, Shi Y, et al. Antisense proline-arginine RAN dipeptides linked to C9ORF72-ALS/FTD form toxic nuclear aggregates that initiate in vitro and in vivo neuronal death. Neuron. 2014;84(6):1213-25.

11. Jiang J, Zhu Q, Gendron TF, Saberi S, McAlonis-Downes M, Seelman A, et al. Gain of Toxicity from ALS/FTD-Linked Repeat Expansions in C9ORF72 Is Alleviated by Antisense Oligonucleotides Targeting GGGGCC-Containing RNAs. Neuron. 2016:90(3):535-50.

12. O'Rourke JG, Bogdanik L, Muhammad AKMG, Gendron TF, Kim KJ, Austin A, et al. C9orf72 BAC Transgenic Mice Display Typical Pathologic Features of ALS/FTD. Neuron. 2015;88(5):892-901.

13. Peters OM, Cabrera GT, Tran H, Gendron TF, McKeon JE, Metterville J, et al. Human C9ORF72 Hexanucleotide Expansion Reproduces RNA Foci and Dipeptide Repeat Proteins but Not Neurodegeneration in BAC Transgenic Mice. Neuron. 2015;88(5):902-9.

14. Liu Y, Pattamatta A, Zu T, Reid T, Bardhi O, Borchelt DR, et al. C9orf72 BAC Mouse Model with Motor Deficits and Neurodegenerative Features of ALS/ FTD. Neuron. 2016;90(3):521-34

15. Zhang YJ, Guo L, Gonzales PK, Gendron TF, Wu Y, Jansen-West K, et al. Heterochromatin anomalies and double-stranded RNA accumulation underlie C9orf72 poly (PR) toxicity. Science. 2019;363(6428).

16. Donnelly CJ, Zhang PW, Pham JT, Haeusler AR, Mistry NA, Vidensky S, et al. RNA toxicity from the ALS/FTD C9ORF72 expansion is mitigated by antisense intervention. Neuron. 2013;80(2):415-28.

17. Lagier-Tourenne C, Baughn M, Rigo F, Sun S, Liu P, Li HR, et al. Targeted degradation of sense and antisense C9orf72 RNA foci as therapy for ALS and frontotemporal degeneration. Proc Natl Acad Sci U S A. 2013;110(47):E4530-9.

18. Sareen D, O'Rourke JG, Meera P, Muhammad AK, Grant S, Simpkinson M, et al. Targeting RNA foci in iPSC-derived motor neurons from ALS patients with a C9ORF72 repeat expansion. Sci Transl Med. 2013;5(208):208ra149.

19. Prudencio M, Belzil W, Batra R, Ross CA, Gendron TF, Pregent LJ, et al. Distinct brain transcriptome profiles in C9orf72-associated and sporadic ALS. Nat Neurosci. 2015;18(8):1175-82.

20. Saksouk N, Simboeck E, Déjardin J. Constitutive heterochromatin formation and transcription in mammals. Epigenetics Chromatin. 2015;8:3

21. Allis $C D$, Jenuwein T. The molecular hallmarks of epigenetic control. Nat Rev Genet. 2016;17(8):487-500.

22. Zeller $\mathrm{P}$, Gasser SM. The Importance of Satellite Sequence Repression for Genome Stability. Cold Spring Harb Symp Quant Biol. 2017;82:15-24.

23. Trojer $P$, Reinberg $D$. Facultative heterochromatin: is there a distinctive molecular signature? Mol Cell. 2007;28(1):1-13.

24. Bannister AJ, Kouzarides T. Regulation of chromatin by histone modifications. Cell Res. 2011;21(3):381-95.

25. Politz JC, Ragoczy T, Groudine M. When untethered, something silent inside comes. Nucleus. 2013;4(3):153-5.

26. Mansuroglu Z, Benhelli-Mokrani H, Marcato V, Sultan A, Violet M, Chauderlier A, et al. Loss of Tau protein affects the structure, transcription and repair of neuronal pericentromeric heterochromatin. Sci Rep. 2016;6:33047.

27. Harr JC, Gonzalez-Sandoval A, Gasser SM. Histones and histone modifications in perinuclear chromatin anchoring: from yeast to man. EMBO Rep. 2016;17(2):13955.

28. Frost $B$, Hemberg M, Lewis J, Feany MB. Tau promotes neurodegeneration through global chromatin relaxation. Nat Neurosci. 2014;17(3):357-66.

29. Hernández-Ortega K, Garcia-Esparcia P, Gil L, Lucas JJ, Ferrer I. Altered Machinery of Protein Synthesis in Alzheimer's: From the Nucleolus to the Ribosome. Brain Pathol. 2016;26(5):593-605.

30. Zheng Y, Liu A, Wang ZJ, Cao Q, Wang W, Lin L, et al. Inhibition of EHMT1/2 rescues synaptic and cognitive functions for Alzheimer's disease. Brain. 2019; 142(3):787-807.

31. Ryu H, Lee J, Hagerty SW, Soh BY, McAlpin SE, Cormier KA, et al. ESET/ SETDB1 gene expression and histone H3 (K9) trimethylation in Huntington's disease. Proc Natl Acad Sci U S A. 2006;103(50):19176-81.
32. Linhoff MW, Garg SK, Mandel G. A high-resolution imaging approach to investigate chromatin architecture in complex tissues. Cell. 2015;163(1):24655.

33. Fritz E, Izaurieta $\mathrm{P}$, Weiss A, Mir FR, Rojas P, Gonzalez D, et al. Mutant SOD1expressing astrocytes release toxic factors that trigger motoneuron death by inducing hyperexcitability. J Neurophysiol. 2013;109(11):2803-14.

34. Rojas F, Cortes N, Abarzua S, Dyrda A, van Zundert B. Astrocytes expressing mutant SOD1 and TDP43 trigger motoneuron death that is mediated via sodium channels and nitroxidative stress. Front Cell Neurosci. 2014:8:24

35. Nagai M, Re DB, Nagata T, Chalazonitis A, Jessell TM, Wichterle $H$, et al. Astrocytes expressing ALS-linked mutated SOD1 release factors selectively toxic to motor neurons. Nat Neurosci. 2007;10(5):615-22.

36. Re DB, Le Verche V, Yu C, Amoroso MW, Politi KA, Phani S, et al. Necroptosis drives motor neuron death in models of both sporadic and familial ALS. Neuron. 2014:81(5):1001-8.

37. Varcianna A, Myszczynska MA, Castelli LM, O'Neill B, Kim Y, Talbot J, et al. Micro-RNAs secreted through astrocyte-derived extracellular vesicles cause neuronal network degeneration in C9orf72 ALS. EBioMedicine. 2019;40:62635.

38. Espana-Agusti J, Warren A, Chew SK, Adams DJ, Matakidou A. Loss of PBRM1 rescues VHL dependent replication stress to promote renal carcinogenesis. Nat Commun. 2017;8(1):2026.

39. Zhang H, Sun L, Wang K, Wu D, Trappio M, Witting C, et al. Loss of H3K9me3 Correlates with ATM Activation and Histone H2AX Phosphorylation Deficiencies in Hutchinson-Gilford Progeria Syndrome. PLoS One. 2016;11(12):e0167454.

40. Hewitson TD, Holt SG, Tan SJ, Wigg B, Samuel CS, Smith ER. Epigenetic Modifications to H3K9 in Renal Tubulointerstitial Cells after Unilateral. Ureteric Obstruction and TGF- $\beta 1$ Stimulation. Front Pharmacol. 2017;8:307.

41. Zhang YM, Gao EE, Wang QQ, Tian H, Hou J. Effects of histone methyltransferase inhibitor chaetocin on histone H3K9 methylation of cultured ovine somatic cells and development of preimplantation cloned embryos. Reprod Toxicol. 2018;79:124-31.

42. Peters AH, Kubicek S, Mechtler K, O'Sullivan RJ, Derijck AA, Perez-Burgos L, et al. Partitioning and plasticity of repressive histone methylation states in mammalian chromatin. Mol Cell. 2003;12(6):1577-89.

43. Peters AH, O'Carroll D, Scherthan H, Mechtler K, Sauer S, Schöfer C, et al. Loss of the Suv39h histone methyltransferases impairs mammalian heterochromatin and genome stability. Cell. 2001;107(3):323-37.

44. Lehnertz B, Ueda Y, Derijck AA, Braunschweig U, Perez-Burgos L, Kubicek S, et al. Suv39h-mediated histone $\mathrm{H} 3$ lysine 9 methylation directs DNA methylation to major satellite repeats at pericentric heterochromatin. Curr Biol. 2003;13(14):1192200.

45. Poleshko A, Smith CL, Nguyen SC, Sivaramakrishnan P, Wong KG, Murray Jl, et al. H3K9me2 orchestrates inheritance of spatial positioning of peripheral heterochromatin through mitosis. Elife. 2019;8.

46. Chen $\mathrm{P}$, Yao JF, Huang RF, Zheng FF, Jiang XH, Chen X, et al. Effect of BIX01294 on H3K9me2 levels and the imprinted gene Snrpn in mouse embryonic fibroblast cells. Biosci Rep. 2015;35(5):e00257.

47. Ugarte F, Sousae R, Cinquin B, Martin EW, Krietsch J, Sanchez G, et al. Progressive Chromatin Condensation and H3K9 Methylation Regulate the Differentiation of Embryonic and Hematopoietic Stem Cells. Stem Cell Reports. 2015;5(5):728-40.

48. Terranova R, Sauer S, Merkenschlager M, Fisher AG. The reorganisation of constitutive heterochromatin in differentiating muscle requires HDAC activity. Exp Cell Res. 2005;310(2):344-56.

49. Vogel-Ciernia A, Wood MA. Examining object location and object recognition memory in mice. Curr Protoc Neurosci. 2014;69:8.31.1-17.

50. Bustos FJ, Ampuero E, Jury N, Aguilar R, Falahi F, Toledo J, et al. Epigenetic editing of the Dlg4/PSD95 gene improves cognition in aged and Alzheimer's disease mice. Brain. 2017;140(12):3252-68.

51. Hayes LR, Rothstein JD. C9ORF72-ALS/FTD: Transgenic Mice Make a ComeBAC. Neuron. 2016:90(3):427-31.

52. Masala A, Sanna S, Esposito S, Rassu M, Galioto M, Zinellu A, Carru C, Carrì MT, laccarino C, Crosio C. Epigenetic Changes Associated with the Expression of Amyotrophic Lateral Sclerosis (ALS) Causing Genes. Neuroscience. 2018;390:1-11.

53. Esanov R, Cabrera GT, Andrade NS, Gendron TF, Brown RH Jr, Benatar M, et al. A C9ORF72 BAC mouse model recapitulates key epigenetic perturbations of ALS/FTD. Mol Neurodegener. 2017;12(1):46.

54. Belzil W, Bauer PO, Prudencio M, Gendron TF, Stetler CT, Yan IK, et al. Reduced C9orf72 gene expression in C9FTD/ALS is caused by histone 
trimethylation, an epigenetic event detectable in blood. Acta Neuropathol. 2013;126(6):895-905.

55. Belzil W, Bauer PO, Gendron TF, Murray ME, Dickson D, Petrucelli L. Characterization of DNA hypermethylation in the cerebellum of C9FTD/ALS patients. Brain Res. 2014;1584:15-21.

56. Belzil W, Katzman RB, Petrucelli L. ALS and FTD: an epigenetic perspective. Acta Neuropathol. 2016;132(4):487-502.

57. Xi Z, Yunusova Y, van Blitterswijk M, Dib S, Ghani M, Moreno D, et al. Identical twins with the C9orf72 repeat expansion are discordant for ALS. Neurology. 2014;83(16):1476-8.

58. Liu EY, Russ J, Wu K, Neal D, Suh E, McNally AG, et al. C9orf72 hypermethylation protects against repeat expansion-associated pathology in ALS/FTD. Acta Neuropathol. 2014;128(4):525-41.

59. McMillan CT, Russ J, Wood EM, Irwin DJ, Grossman M, McCluskey L, et al. C9orf72 promoter hypermethylation is neuroprotective: Neuroimaging and neuropathologic evidence. Neurology. 2015;84(16):1622-30.

60. Bannister AJ, Zegerman P, Partridge JF, Miska EA, Thomas JO, Allshire RC, et al. Selective recognition of methylated lysine 9 on histone H3 by the HP1 chromo domain. Nature. 2001;410(6824):120-4.

61. Lachner M, O'Carroll D, Rea S, Mechtler K, Jenuwein T. Methylation of histone H3 lysine 9 creates a binding site for HP1 proteins. Nature. 2001; 410(6824):116-20.

62. Regha K, Sloane MA, Huang R, Pauler FM, Warczok KE, Melikant B, et al. Active and repressive chromatin are interspersed without spreading in an imprinted gene cluster in the mammalian genome. Mol Cell. 2007;27(3): 353-66.

63. Zeller P, Padeken J, van Schendel R, Kalck V, Tijsterman M, Gasser SM. Histone H3K9 methylation is dispensable for Caenorhabditis elegans development but suppresses RNA:DNA hybrid-associated repeat instability. Nat Genet. 2016:48(11):1385-95.

64. Wijchers PJ, Geeven G, Eyres M, Bergsma AJ, Janssen M, Verstegen M, et al. Characterization and dynamics of pericentromere-associated domains in mice. Genome Res. 2015;25(7):958-69.

65. Sun W, Samimi H, Gamez M, Zare H, Frost B. Pathogenic tau-induced piRNA depletion promotes neuronal death through transposable element dysregulation in neurodegenerative tauopathies. Nat Neurosci. 2018;21(8): 1038-48.

66. Rojas F, Gonzalez D, Cortes N, Ampuero E, Hernández DE, Fritz E, et al. Reactive oxygen species trigger motoneuron death in non-cell-autonomous models of ALS through activation of c-Abl signaling. Front Cell Neurosci. 2015;9:203.

67. Nakata H. Morphology of mouse seminiferous tubules. Anat Sci Int. 2019; 94(1):1-10.

\section{Publisher's Note}

Springer Nature remains neutral with regard to jurisdictional claims in published maps and institutional affiliations.

Ready to submit your research? Choose BMC and benefit from:

- fast, convenient online submission

- thorough peer review by experienced researchers in your field

- rapid publication on acceptance

- support for research data, including large and complex data types

- gold Open Access which fosters wider collaboration and increased citations

- maximum visibility for your research: over $100 \mathrm{M}$ website views per year

At $\mathrm{BMC}$, research is always in progress.

Learn more biomedcentral.com/submissions 